\title{
Corrigendum: Bmi1 limits dilated cardiomyopathy and heart failure by inhibiting cardiac senescence
}

I. Gonzalez-Valdes, I. Hidalgo, A. Bujarrabal, E. Lara-Pezzi, L. Padron-Barthe, P. Garcia-Pavia, Pablo Gómez-del Arco, J.M. Redondo, J.M. Ruiz-Cabello, L.J. Jimenez-Borreguero, J.A. Enriquez, J.L. de la Pompa, A. Hidalgo \& S. Gonzalez

Nature Communications 6:6473 doi: 10.1038/ncomms7473 (2015); Published online 9 Mar 2015; Updated 14 May 2015

In the original version of this Article, the last name of the author Pablo Gómez-del Arco was incorrectly given as Gomez, and the affiliation details were incorrect. This has now been corrected in both the PDF and HTML versions of the Article. 